\title{
Assessment of Temporal Distribution of Noise Pollution in Delhi using ArcGIS
}

\author{
Raunak Sinha ${ }^{1 *}$ \\ ${ }^{1}$ Department of Environmental Engineering, Delhi Technological University, Delhi, India. \\ ${ }^{1}$ raunaksinha_2k19ene03@dtu.ac.in
}

\begin{abstract}
Noise pollution affects day-to-day life both mentally and physically. Hence, it's a growing problem in every major city of the world. Many diseases have been proven to be associated directly with rise in noise level. To combat the noise level government agencies have laid down certain guidelines which suggest noise level in different location to be in prescribed limits. These noise limits is different for different land-use pattern and also different for different timings also. Daytime generally experiences more noise level than night time in almost all the locations. In present study, noise level of a particular day of $24 \mathrm{hr}$ is taken from 26 locations. These noise levels are used to construct noise map in ArcGIS for Delhi for both daytime ad night time. These noise maps are used to present a comparative study of noise pollution between daytime and night time. Research Study suggest that in the daytime most of the area of Delhi experiences 55-60 dB noise level while in the night time it is experienced that most of the location in Delhi, noise level is 50-55 dB.
\end{abstract}

Keywords: ArcGIS, Noise map, Land-use pattern

*Corresponding Author: Raunak Sinha: Email: raunaksinha_2k19ene03@dtu.ac.in; Contact +91-8800874063 


\section{Introduction}

Noise Pollution in today's world is regarded as one of the most discussed problem as a result of ongoing technological advancement. Noise has a multitude of detrimental effects on our daily lives, including discomfort, sleep disruption, study disruption and headache. Sources of noise include: Traffic noise, construction activities, industrial activities and ceremonial functions.

Noise levels at different locations vary depending on the ambience or surrounding landscape. A highly urbanized commercial location will have high noise level as compared to a residential location, hence depending upon the landuse pattern, C.P.C.B has declared noise level standard for different locations in India. Also, it has been seen that daytime and nighttime noise level also vary within a given location as ongoing activities reduces during nighttime. Studies have shown that daytime noise level are higher than nighttime noise. Delhi being among the noisiest city of the world has no different picture as according to DPCC noise level were found to be higher than those set as standard values.

The city of Varanasi's noise level monitoring indicated that traffic is the biggest source of noise pollution. Noise levels are higher than the Central Pollution Control Board's recommended value at all sampling sites. One field experiment showed that places with vegetation have less noise level than that with less vegetation[1]. Another study found that the noise level in the morning at the residential area was higher than the authorised standard, reaching up to $84.8 \mathrm{~dB}(\mathrm{~A})$, in compared to the commercial regions, which remained at $79.46 \mathrm{~dB}$. (A)[2]. On the three monitoring days, average noise levels in the industrial, commercial, residential, and silent zones were 2.38, 8.62, 7.37, and $3.97 \mathrm{~dB}$ higher than $\mathrm{CPCB}$ norms during the day, and 1.18, 2.42, 5.40, and $6.07 \mathrm{~dB}$ higher during the night, respectively, than CPCB standards.[3].[4] Chauhan in their study also reported daytime noise level to be higher than night time noise level at different locations based on landuse pattern.[5]Another study reported noise level difference of $11-21 \mathrm{~dB}$ between daytime and nightime noise level from 6 different locations.

\subsection{Noise Study using GIS}

Noise maps, according to research, can simply aid in the assessment of noise levels and their outcomes based on locations, people density, and building type[6]. The city of Santiago de Chile was mapped in terms of traffic noise. [7] [8] Cai combined GIS and GPS to create traffic noise maps for day and nighttime highways in Guangzhou. In Curitiba, Brazil, noise pollution was studied using noise measurements and acoustic mapping[9]. According to another study[10], noise levels in the English Bazaar Municipality in West Bengal exceed 70 decibels at around 39.21 percent and 22.86 percent of the total area, respectively. [11] 
Banerjee created noise maps to illustrate the temporal and spatial distribution of noise in Asansol City, West Bengal, and found that noise levels ranged from moderate to extremely high when compared to C.P.C.B norms. [12] Another study gave an overview of GIS-based road traffic noise mapping methodologies, whereas Tiwari [13] looked at the spatial aspects of urban environmental noise using noise maps created from several noise monitoring sites.

\section{Methodology}

In this research paper GIS approach is used to compare the noise scenario comparison of Delhi of day and night time. GIS application ArcMap is presently the handiest software used these days to effectively display and compare the two noise maps using the geographical coordinates of instruments present at different location.

\subsection{Site Selection}

Noise level from different location have been taken of both daytime and night time. Noise level at these locations have been taken from DPCC website. There are 26 Noise Monitoring locations based on different land use pattern. Out of 26 locations,5 is silent zone ,5 industrial,7-residential area and 9 commercial locations.

\subsection{Data Collection}

Noise data over a period of 24 hours has been taken from real time monitoring noise data of DPCC website. Noise level taken is L(A) eq which is standard for human ear.

\begin{tabular}{|c|c|c|c|c|}
\hline Name & Latitude & Longitude & L(Day) & L(Night) \\
\hline Alipur & 28.81576788 & 77.1503023 & 46.9 & 46 \\
\hline Jahangirpuri & 28.7313369 & 77.1669649 & 59 & 53.6 \\
\hline Narela & 28.8229345 & 77.1003429 & 63.2 & 58.9 \\
\hline Sonia Vihar & 28.7098209 & 77.2475681 & 55 & 52.5 \\
\hline Patparganj & 28.6220384 & 77.2831687 & 56 & 53 \\
\hline Ashok Vihar & 28.6958571 & 77.1793725 & 57.7 & 53.5 \\
\hline Nehru Nagar & 28.5657933 & 77.2507223 & 56.5 & 52.9 \\
\hline Sri Aurobindo Marg & 28.5288658 & 77.1870476 & 55.9 & 48.8 \\
\hline
\end{tabular}




\begin{tabular}{|l|l|l|l|l|}
\hline Najafgarh & $\mathbf{2 8 . 5 7 2 1 2 2}$ & $\mathbf{7 6 . 9 3 1 2 7 6 7}$ & $\mathbf{4 9 . 6}$ & $\mathbf{4 8 . 4}$ \\
\hline Vivek Vihar & $\mathbf{2 8 . 6 8 4 4 7 8 4}$ & $\mathbf{7 7 . 2 9 5 9 3 7 5}$ & $\mathbf{6 0 . 6}$ & $\mathbf{5 5 . 4}$ \\
\hline PUSA & $\mathbf{2 8 . 6 3 0 9 0 2 4}$ & $\mathbf{7 7 . 1 5 1 0 6 2 8}$ & $\mathbf{6 3 . 2}$ & $\mathbf{5 7 . 8}$ \\
\hline National Stadium & $\mathbf{2 8 . 6 1 3 4 0 6 2}$ & $\mathbf{7 7 . 2 3 6 2 3 3 4}$ & $\mathbf{6 6 . 8}$ & $\mathbf{5 1 . 6}$ \\
\hline J.L.N Stadium & $\mathbf{2 8 . 5 8 2 8 4 5 6}$ & $\mathbf{7 7 . 2 3 2 1 7 7 8}$ & $\mathbf{5 7 . 2}$ & $\mathbf{5 1 . 3}$ \\
\hline $\begin{array}{l}\text { Dr. Karni Singh Shooting } \\
\text { Range }\end{array}$ & $\mathbf{2 8 . 4 9 9 7 2 6 8}$ & $\mathbf{7 7 . 2 6 4 9 0 6 7}$ & $\mathbf{5 6 . 1 0}$ & $\mathbf{5 2 . 6 0}$ \\
\hline Dwarka & $\mathbf{2 8 . 5 7 6 9 0 9 1}$ & $\mathbf{7 7 . 0 7 3 7 0 8 9}$ & $\mathbf{6 5 . 1 0}$ & $\mathbf{5 9 . 1 0}$ \\
\hline Mundka & $\mathbf{2 8 . 6 8 4 9 4}$ & $\mathbf{7 7 . 0 1 9 9 9 8}$ & $\mathbf{5 5 . 5 0}$ & $\mathbf{5 7 . 2 0}$ \\
\hline Rohini Sector 16 & $\mathbf{2 8 . 7 3 2 8 2 1 9}$ & $\mathbf{7 7 . 1 1 6 6 4 9 7}$ & $\mathbf{5 4 . 8 0}$ & $\mathbf{4 9 . 3 0}$ \\
\hline Wazirpur & $\mathbf{2 8 . 7 0 0 4 8 5 9}$ & $\mathbf{7 7 . 1 6 3 2 7 1}$ & $\mathbf{6 3 . 3 0}$ & $\mathbf{5 7 . 8 0}$ \\
\hline Okhla Ph-II & $\mathbf{2 8 . 5 3 1 3 1 4}$ & $\mathbf{7 7 . 2 6 8 4 9 7 3}$ & $\mathbf{5 5 . 2 0}$ & $\mathbf{5 2 . 1 0}$ \\
\hline Bawana & $\mathbf{2 8 . 7 7 5 7 9 5 9}$ & $\mathbf{7 7 . 0 4 6 2 9 3 2}$ & $\mathbf{5 3 . 8 0}$ & $\mathbf{4 7 . 0 0}$ \\
\hline Kahmere Gate & $\mathbf{2 8 . 6 6 7 4 8 6 5}$ & $\mathbf{7 7 . 2 2 4 4 8 4 8}$ & $\mathbf{6 5 . 3 0}$ & $\mathbf{6 2 . 6 0}$ \\
\hline Lajpat Nagar & $\mathbf{2 8 . 6 4 4 5 6 3 1}$ & $\mathbf{7 7 . 2 8 0 8 1 3 2}$ & $\mathbf{6 3 . 5 0}$ & $\mathbf{5 3 . 8 0}$ \\
\hline Lodhi Road & $\mathbf{2 8 . 5 8 9 3 0 3 9}$ & $\mathbf{7 7 . 2 1 9 2 6 2 8}$ & $\mathbf{4 9 . 3 0}$ & $\mathbf{4 3 . 8 0}$ \\
\hline Shahadra & $\mathbf{2 8 . 6 7 0 1 5 9 7}$ & $\mathbf{7 7 . 2 7 8 9 3 4 1}$ & $\mathbf{6 8 . 7 0}$ & $\mathbf{6 6 . 0 0}$ \\
\hline Karol Bagh & $\mathbf{2 8 . 6 5 1 7 9 8 1}$ & $\mathbf{7 7 . 1 8 4 5 6 6 9}$ & $\mathbf{7 4 . 6 0}$ & $\mathbf{6 4 . 0 0}$ \\
\hline Connaught Place & $\mathbf{2 8 . 6 3 1 7 6 1}$ & $\mathbf{7 7 . 2 1 6 5 2 9 5}$ & $\mathbf{6 3 . 7}$ & $\mathbf{5 7 . 6}$ \\
\hline
\end{tabular}

Table 1: Data taken from DPCC Real time noise monitoring data of 24 hour from 26 locations

\subsection{Noise Map Development}

Noise map have been developed using these noise levels in ArcMap 10.8 software. ArcMap is a state-of-the-art software by ESRI, USA. ArcMap is a digital platform to perform various analysis using various inputs. ArcMap helps to create a pictorial representation of the input provided as Noise-Map. Noise levels from all the station are compiled in an excel sheet along with their longitude and latitude location to form a comma delimated value file. This csv file is used as an input in ArcMap to develop noise-map. After applying the csv file a shapefile of Delhi boundary is added to the ArcMap interface to cover all the instrument points inside Delhi shapefile. Now IDW interpolation is used develop the pictorial representation of noise 
surface throughout Delhi. This Noise-Map is further analysed to compare the temporal difference of noise-map developed for both daytime and night time.

\subsection{Tools\& Techniques}

ArcMap is used to develop noise-map is one of the rapidly developing recognition among researchers over the past few years. This is due to easy user interface of ESRI developed ArcMap and easy to learn options available. Due to the multiple options it offers to perform several analysis it is quickly gaining trust of the researches for any research article. In ArcMap, there are different techniques offered to develop of surface envelope of a particular scalar quantity over a particular area, one such technique is IDW interpolation. IDW interpolation stands for Inverse Difference weightage. It

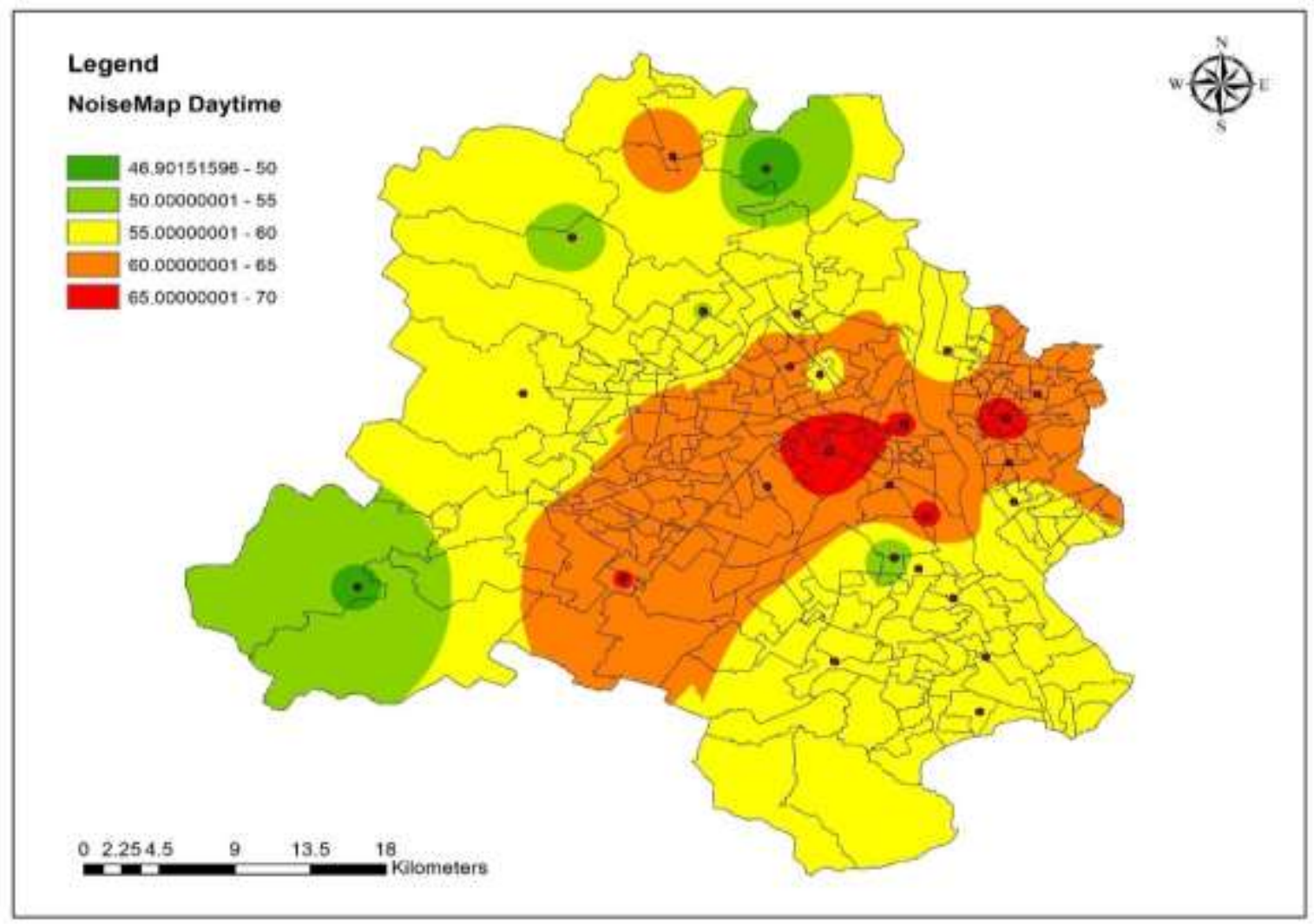

Figure 1: Noise map constructed using Daytime Noise level 


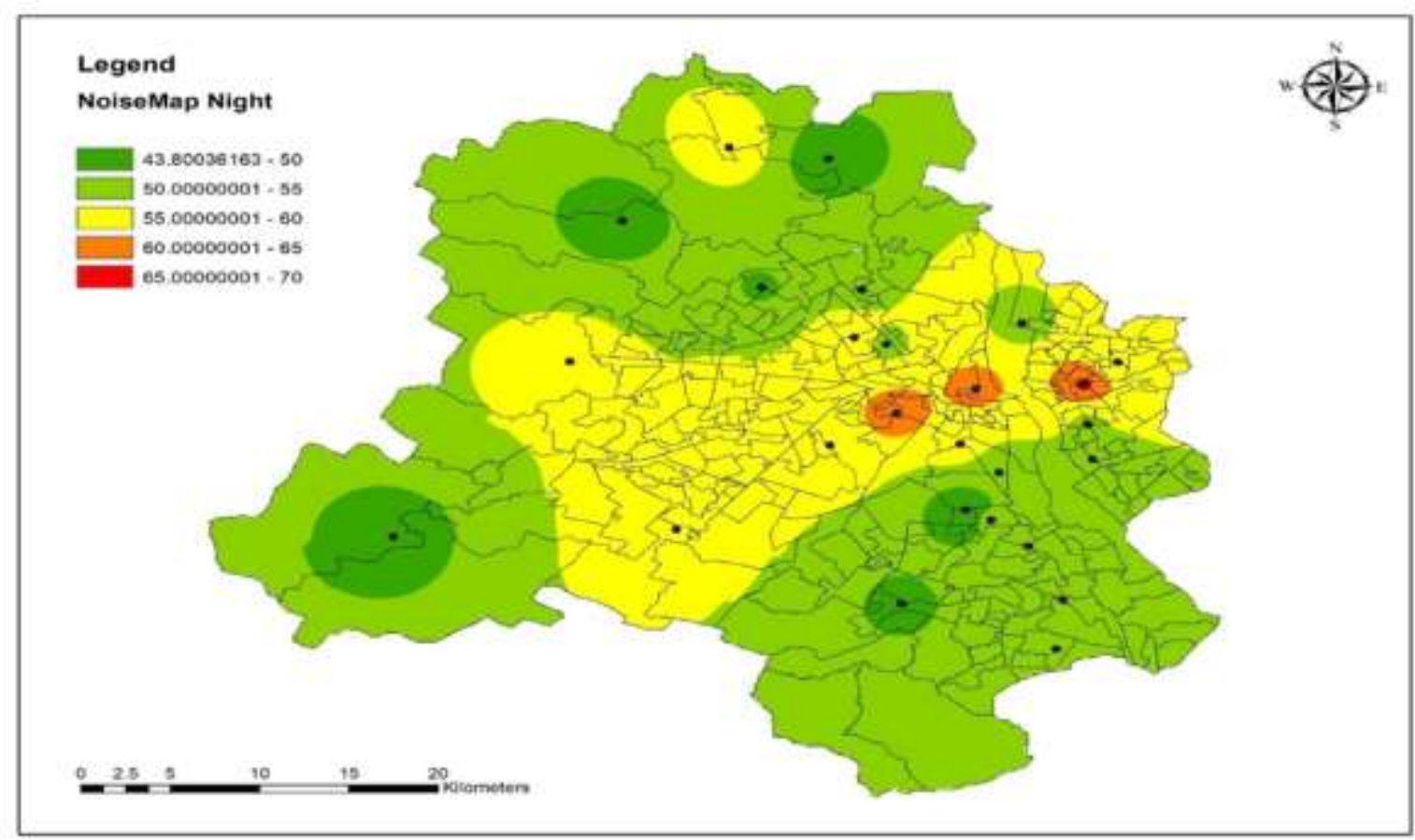

Figure 2: Noise map constructed using Night time Noise level of Delhi

\section{Result}

Noise maps developed using ArcMap was used to compare the temporal distribution of noise pollution in the city. As noise map comparison suggests noise level in the daytime was usually more as compared to night. The key findings were that in daytime noise level used to remain between 55-60 dB in most of the locations in Delhi while in night noise level between $50-55 \mathrm{~dB}$ is most common.

\begin{tabular}{|l|l|l|}
\hline Noise Level Category(dB) & Daytime (Area exposed) & Nightime (Area exposed) \\
\hline$>50 \mathrm{~dB}$ & $15 \mathrm{Km}^{2}$ & $120 \mathrm{Km}^{2}$ \\
\hline $50-55 \mathrm{~dB}$ & $201.42 \mathrm{Km}^{2}$ & $887.68 \mathrm{Km}^{2}$ \\
\hline $55-60 \mathrm{~dB}$ & $856.26 \mathrm{Km}^{2}$ & $468.80 \mathrm{Km}^{2}$ \\
\hline $60-65 \mathrm{~dB}$ & $421.25 \mathrm{Km}^{2}$ & $21.96 \mathrm{Km}^{2}$ \\
\hline $65-70 \mathrm{~dB}$ & $4.51 \mathrm{Km}^{2}$ & $0 \mathrm{Km}^{2}$ \\
\hline
\end{tabular}

Table 2. Noise level Category distribution of Delhi in both daytime and night time 


\section{Conclusion}

The temporal distribution of noise-level in Delhi also suggests that noise level in daytime is higher than noise-level during night time. While only $15 \mathrm{Km} 2$ of area is experiencing noiselevel below $50 \mathrm{~dB}$ during daytime this increases to $120 \mathrm{Km} 2$ in the night suggesting that noise level reduces during night. In the night major portion of area i.e $887.68 \mathrm{Km} 2$ is experiencing noise level of 50-55 dB while in the daytime area experiencing this noise level is only $201.42 \mathrm{Km} 2$. While in the daytime major chunk of area is experiencing $55-60 \mathrm{~dB}$ noise, this range decreases in the night as $468.80 \mathrm{Km} 2$ area is experiencing noise level in this zone. In 60-65 dB noise category, in the daytime $421.25 \mathrm{Km} 2$ area is falling in this category while it decreases to only $21.96 \mathrm{Km} 2$ in the night suggesting night time noise level remains in the low noise level category. In the $65-70 \mathrm{~dB}$ noise category none of the area from night time falls in this noise category while only $4.51 \mathrm{Km} 2$ area in the daytime experiences this noise level. 


\section{References}

[1] V. Pathak, B. D. Tripathi, and V. K. Mishra, "Dynamics of traffic noise in a tropical city Varanasi and its abatement through vegetation,” Environ. Monit. Assess., vol. 146, no. 1-3, pp. 67-75, 2008, doi: 10.1007/s10661-007-0060-1.

[2] P. Alam, K. Ahmad, and N. Akhtar, "Temporal and spatial fluctuation of noise levels in the closed vicinity of urban roadways,” Int. J. Recent Technol. Eng., vol. 8, no. 3, pp. 5983-5989, 2019, doi: 10.35940/ijrte.C5914.098319.

[3] S. B. Mangalekar, A. S. Jadhav, and P. D. Raut, "Study of Noise Pollution in Kolhapur City, Maharashtra, India Abstract :," Online, vol. 2, no. 1, pp. 65-69, 2012.

[4] A. Chauhan, M. Pawar, D. Kumar, N. Kumar, and R. Kumar, "Assessment of Noise Level Status in Different Areas of Moradabad City,” Researcher, vol. 2, no. 5, pp. 88-90, 2010.

[5] S. Vikas, B. Gaurav, and M. Gagan, “Assessment of ambient Noise level in the city of Bareilly ( U . P .),” vol. II, no. 2, pp. 8-15, 2011.

[6] M. T. Obaidat, "Spatial Mapping of Traffic Noise Levels in Urban Areas," J. Transp. Res. Forum, vol. 47, no. 2, pp. 89-102, 2011, doi: 10.5399/osu/jtrf.47.2.1711.

[7] E. Suárez and J. L. Barros, "Traffic noise mapping of the city of Santiago de Chile," Sci. Total Environ., vol. 466467, pp. 539-546, 2014, doi: 10.1016/j.scitotenv.2013.07.013.

[8] M. Cai, J. Zou, J. Xie, and X. Ma, "Road traffic noise mapping in Guangzhou using GIS and GPS," Appl. Acoust., vol. 87, no. January, pp. 94-102, 2015, doi: 10.1016/j.apacoust.2014.06.005.

[9] P. E. K. Fiedler and P. H. T. Zannin, "Evaluation of noise pollution in urban traffic hubs-Noise maps and measurements," Environ. Impact Assess. Rev., vol. 51, pp. 1-9, 2015, doi: 10.1016/j.eiar.2014.09.014.

[10] P. Das, S. Talukdar, S. Ziaul, S. Das, and S. Pal, "Noise mapping and assessing vulnerability in meso level urban environment of Eastern India," Sustain. Cities Soc., vol. 46, no. January, p. 101416, 2019, doi: 10.1016/j.scs.2019.01.001.

[11] D. Banerjee, S. K. Chakraborty, S. Bhattacharyya, and A. Gangopadhyay, “Appraisal and mapping the spatialtemporal distribution of urban road traffic noise,” Int. J. Environ. Sci. Technol., vol. 6, no. 2, pp. 325-335, 2009, doi: 10.1007/BF03327636.

[12] D. R. Sonaviya and B. N. Tandel, “A Review on GIS-Based Approach for Road Traffic Noise Mapping,” Indian J. Sci. Technol., vol. 14, no. 12, pp. 1-6, 2019, doi: 10.17485/ijst/2019/v12i14/132481.

[13] K. Tiwari, B. Tandel, S. Vallabhbhai, S. K. Jha, and B. N. Tandel, "GIS based approach for noise mapping of urban road traffic,” Nap-2017, S.V.N.I.T., no. August, p. 8, 2017, [Online]. Available: https://www.researchgate.net/publication/319261157. 